\title{
Tempos passados em James Stuart Archive: recontando histórias, entrelaçando narrativas
}

\author{
Gabriela Aparecida dos Santos* \\ Universidade de São Paulo, São Paulo-SP, Brasil
}

Webb, Colin de Berri; Wright, John Britten. The James Stuart Archive of recorded oral evidence relating to the history of the zulu and neighbouring peoples. Pietermaritzburg: University of Natal Press and Durban: Killie Campbell Africana Library, v. 6, 2014.

O grandioso esforço em publicar o material original que compóe a coleção James Stuart, sob a guarda da Killie Campbell Africana Library, em Durban, na África do Sul, ganhou, em agosto de 2014, um novo (e sexto) volume que dá sequência ao trabalho dos professores John Wright, da Universidade de Witwatersrand, e Colin Webb, da Universidade de Natal, iniciado em 1976.

James Stuart nasceu em 1868, em Pietermaritzburg, e os primeiros anos de sua vida foram passados nas vilas de Greytown e Ixopo, onde começou a aprender a língua isiZulu. Em função de sua proficiência, logo foi nomeado intérprete e escriturário do Magistrado Residente em Eshowe, na recém-anexada colônia britânica da Zululândia, iniciando, assim, a sua carreira na "administração dos nativos" em 1888. ${ }^{1}$ Em 1895, ele

\footnotetext{
${ }^{1}$ WRIGHT, John Britten. Making the James Stuart Archive. History in Africa. Cambridge: Cambridge
}

próprio assumiu o lugar de Magistrado na Zululândia, em Ingwavuma, e quando, em 1906, irrompeu o confronto com as forças de Bambatha, serviu no campo de artilharia de Natal e no serviço de inteligência colonial.

Em 1909, foi nomeado Assistant Secretary for Native Affairs, em Pietermaritzburg, ocupando o segundo posto mais alto do Native Affairs Department, mas no ano seguinte, após Natal se tornar uma província na nova União Sul-Africana e o Native Affairs Department ser incorporado em uma estrutura nacional, Stuart foi transferido para Pretória, onde se manteve até 1912, ano em que se aposentou. Em 1913, publicou $A$ history of the zulu rebellion (1906) e nas décadas seguintes passou a se dedicar à escrita de textos em isiZulu, distribuídos nas escolas de Natal ao menos até a década de $1940 .^{2}$ James Stuart faleceu em Londres, em 1942.

James Stuart teria demonstrado interesse crescente na língua isiZulu e nas histórias de seus falantes ainda nos anos de 1880 . $\mathrm{Na}$ década seguinte, enquanto ascendia na

University Press, 1996, v. 23, p. 334.

2 WRIGHT, John Britten. Socwatsha kaPhaphu, James Stuart and their conversations on the past, 1897-1922. Kronos: southern african histories. Cape Town: University of Western Cape, 2015, v. 41, p. 142-165.

DOI - http://dx.doi.org/10.1590/2237-101X017033015

* Doutoranda no Programa de Pós-graduaçáo em História Social da Faculdade de Filosofia, Letras e Ciências Humanas da Universidade de São Paulo. Bolsista Fapesp. E-mail: gabriela.historia@usp.br. 
administração das "populaçóes nativas", Stuart desenvolveu uma perspectiva que desaprovava a política colonial adotada, considerando que a sociedade "tradicional" africana se desagregava ao contato com a sociedade branca "civilizada", fazendo declinar o poder de chefes que Stuart, tal como outros administradores, viam como sendo um dos principais suportes de mediação. Para ele, o processo era agravado pela má administração dos europeus, devida não à suposta maldade ou obstinação, mas à ignorância em relação aos "costumes" africanos. A solução, em sua opinião, seria educar os colonos brancos, sobretudo os mais influentes entre eles, para uma melhor compreensão das instituições africanas. ${ }^{3}$

James Stuart tomou para si a tarefa e, entre 1897 e 1924, entrevistou cerca de duzentos informantes africanos, abordando temas referentes às histórias dos falantes de isiZulu e outros grupos. As entrevistas foram registradas por escrito, intercalando passagens em inglês e isiZulu e, em muitos casos, recorrendo à combinação de ambas as línguas. De um modo particularmente meticuloso, Stuart anotou os nomes de seus informantes e daqueles que os acompanhavam, fornecendo o local e a data das entrevistas, e referenciando outras fontes que considerasse relevantes.

Após a sua morte, o material resistiu aos ataques aéreos durante a Segunda Guerra Mundial (1939-1945), guardado no porão de sua casa no sudeste de Londres. Em 1947, a viúva de James Stuart encaminhou o con-

\footnotetext{
${ }^{3}$ Ibidem, op. cit. Kronos: southern african histories (1996), p. 335.
}

junto para Killie Campbell (1881-1965), conhecida colecionadora de livros em Durban, na expectativa de que pudesse encontrar um editor que se dispusesse a trabalhá-lo. Em 1949, Campbell decidiu, ela própria, comprá-lo e incorporá-lo à biblioteca que mantinha em sua casa, e que passou para a custódia da Universidade de Natal em $1965 .{ }^{4}$ Assim conservada na atual Killie Campbell Africana Library, a soma de entrevistas integra o núcleo do James Stuart Collection, que inclui ainda correspondência pessoal e outros manuscritos.

Em 1970, o professor Colin Webb apresentou à biblioteca um projeto de publicação das entrevistas realizadas por James Stuart, passando a trabalhar com John Wright, selecionado pelo Departamento de História e Ciência Política da Universidade de Natal para a vaga de pesquisador assistente. Em 1976, foi impresso o volume I, seguido dos demais: II (1979); III (1982); IV (1986); V (2001); e, finalmente, o VI em 2014, estando previsto um sétimo, com os poemas de enaltecimento entoados por interlocutores de Stuart e omitidos na edição dos tomos anteriores.

Em 1988, o professor Julian Cobbing, da Universidade de Rhodes, escreveu uma resenha questionando a validade da coleção como fonte documental, ao destacar o papel de James Stuart na produção do "conteúdo histórico" de suas entrevistas, informado por "fantasias" de outros escritores de sua época e determinado por uma geração "que havia internalizado todos os pressupostos de superioridade da civilização branca" — " "nada do

\footnotetext{
${ }^{4}$ Idem.
} 
que os informantes lhe contavam, contradizendo o estabelecido pelas autoridades, produzia efeito sobre ele". Reavivando as "tradiçôes" colhidas por James Stuart, os volumes organizados por Colin Webb e John Wright seguiriam ecoando em "uníssono" o mesmo esforço, cujo "enigma central era desvendar a forma como o nativo podia ser despojado de sua terra e posto a trabalhar, administrado, controlado, separado e ordenado, tratado como uma criança, empobrecido e desumanizado". 5

De acordo com Carolyn Hamilton, professora da Universidade de Cape Town, Julian Cobbing estava correto ao enfatizar o impacto e a influência das partes envolvidas nas entrevistas, mas equivocado em dois pontos importantes. Para ela (e apesar do interesse recorrente de James Stuart em tópicos como a ascensão de Shaka, direcionando os informantes para o tema), a multiplicidade de pontos de vista e o modo como diferiam de suas próprias versóes são "fortemente sugestivos da integridade de suas técnicas de registro". ${ }^{6}$

Do mesmo modo, seria impreciso descrever Stuart como um "representativo e influente produto de uma desagradável geraçáo" ou tomá-lo como um administrador racista que supervisionava "ocupações de terra e cobrança de impostos e arbitrava en-

${ }^{5}$ COBBING, Julian. A tainted well. The objectives, historical fantasies and working methods of James Stuart. Journal of Natal and zulu history. Pietermaritzburg: University of KwaZulu-Natal Press, 1988, v. XI, p. 119-124; 135. (tradução livre).

${ }^{6}$ HAMILTON, Carolyn. James Stuart and "the establishment of a living source of tradition". Seminar paper. University of the Witwatersrand, 1994, p. 2; 20-21. (tradução livre) tre africanos em assuntos de sua própria lei e costume, usurpando as funçóes e os poderes de alguns dos muitos chefes que ele estava entrevistando". ' Em sua análise, a autora sublinha a complexidade da carreira de James Stuart, atrelando-a ao desenvolvimento das políticas voltadas para os "nativos" e à posição, por vezes ambígua, de seus primeiros formuladores.

Ao examinar o vasto conjunto de manuscritos não publicados, como diários, rascunhos, correspondências e notas pessoais, Hamilton identificou um James Stuart particularmente desencantado com as políticas voltadas para os "nativos" (ainda que fortemente atrelado ao discurso de seu próprio tempo) e comprometido em ouvir os "africanos": "a questão do contato entre as raças civilizadas e não civilizadas recebe a sua expressão quase inteiramente dos civilizados. (...) A voz do homem não civilizado nunca é ouvida. De toda forma, ela não pode ser detectada no meio de toda a Babel atual e muito menos por pessoas que nada conhecem sobre a situação a partir do ponto de vista do nativo. Em uma questão desse tipo, as vozes das pessoas que são diretamente afetadas são, certamente, de grande importância".

Desde 1897, em Eshowe, James Stuart procurava ouvir essas vozes. Em 1900, após atuar em Ingwavuma e um curto período como cônsul britânico na Suazilândia entre

${ }^{7}$ COBBING, Julian apud HAMILTON, Carolyn. James Stuart and "the establishment of a living source of tradition”, op. cit., p. 2-3. (traduçáo livre) ${ }^{8}$ Stuart Papers, file 42, item XXI - Killie Campbell Africana Library apud HAMILTON, Carolyn. James Stuart and "the establishment of a living source of tradition”, op. cit., p. 3. (tradução livre) 
1898 e 1899, ele estava em Ladysmith, novamente na função de magistrado, e foi nesse ponto que passou a se encontrar com integrantes da comunidade kholwa, ${ }^{9}$ como John Kumalo, ouvindo e anotando as suas queixas contra o governo e a administração dos "nativos". As reunióes no quarto do hotel em que James Stuart estava hospedado teriam levado Kumalo a comentar sobre a sua originalidade, chamando o local de "KwaSogekle" - literalmente, "o lugar do labirinto", desenhado pela saliva dos mais velhos reunidos em discussão, fumando cânhamo. ${ }^{10}$

A partir de Ladysmith, James Stuart defenderia o argumento de que a chave da política voltada para os "nativos" estava em agregar um maior conhecimento e entendimento das "instituiçóes e práticas africanas", tornando-se um "refrão constante em seus escritos e a força motivadora" de suas entrevistas. Por esse percurso, Stuart podia defender a superioridade dos europeus e clamar por equidade de oportunidades para os africanos em um mesmo documento: em parte como resultado de sua imersão e habilidade linguística em isiZulu, Stuart intermediava os mundos africanos e europeus enquanto se movia, buscando não apenas implementar políticas coloniais, mas modelá-las segundo

\footnotetext{
${ }^{9}$ Grupo formado por falantes de isiZulu convertidos ao cristianismo e ao qual estavam vinculados os líderes dos movimentos que dariam origem ao Inkhata e ao Congresso Nacional Africano. Cf. HOULE, Robert J. Becoming amakholwa: revival and the formation of group identity on the stations of the American Zulu Mission, 1890-1910. History and African Studies Seminar Paper. University of Natal, 2001.

${ }^{10}$ HAMilTON, Carolyn. James Stuart and "the establishment of a living source of tradition”, op. cit., p. 6-7. (tradução livre)
}

a compreensão que formava no contato com os seus interlocutores. ${ }^{11}$

Após a formação da União Sul-Africana, em 1910, o centro das decisóes na esfera dos "assuntos nativos" deslocou-se, gradualmente, para Pretória e para funcionários menos interessados nos conhecimentos de James Stuart sobre os "africanos". Para o editor John Wright, o otimismo de Stuart no sentido de "educar" os administradores se dissipou nos anos seguintes à sua nomeação como Assistant Secretary for Native Affairs, precipitando o seu pedido de aposentadoria em 1912. E quando, terminada a Primeira Guerra Mundial (1914-1918), ele se envolveu em seu último conjunto de entrevistas, o objetivo parece ter sido menos o de "iluminar" os seus pares do que o de educar estudantes falantes de isiZulu — "em uma espécie de anticlímax de seus anos de pesquisa, ele publicou uma seleção de seus testemunhos não em um opus magnum, mas em cinco livros escolares". ${ }^{2}$

O entendimento da complexa relação de poderes em que se situava James Stuart permite analisar também as entrevistas como narrativas fluidas (e menos como fonte de fatos fixos e encadeados), cujo conteúdo variava de acordo com as circunstâncias sociais e políticas em que eram enunciadas, com os seus interlocutores compondo elaborados argumentos sobre o passado e o presente. ${ }^{13}$

\footnotetext{
${ }^{11}$ Ibidem, p. 10-23. (tradução livre)

${ }^{12}$ WRIGHT, John Britten. Making the James Stuart Archive, op. cit. (1996), p. 336-337.

13 Cf. "Preface". In: WEBB, Colin de Berri; WRIGHT, John Britten. The James Stuart Archive of recorded oral evidence relating to the history of the zulu and neighbouring peoples. Pietermaritzburg: University of Natal Press and Durban: Killie
} 
Em 31 de maio de 1903, como é possível acompanhar no sexto (e novo) volume da coleção, James Stuart encontrava-se em Durban, ouvindo Tununu kaNonjiya contar que “...os bôeres [comandados por Piet Retief] tinham vindo a Dingana [em outubro de 1837] para pedir a entrega do gado apreendido na ofensiva a Mzilikazi. [Que] Dingana estava preparado para dar-lhes estas coisas (...) [mas] o gado apreendido de Mzilikazi já tinha sido distribuído e, portanto, não era possível restituí-lo". ${ }^{14}$ De um modo muito tênue, a anotação de James Stuart imediatamente a seguir insere o encontro em um contexto envolvendo ainda a reivindicação de terras, além do gado, embora sem marcar, formal e textualmente, de que se tratava de um complemento pessoal e não de uma observação feita por Tununu: "os bôeres cometeram um erro avançando com duas requisiçóes ao mesmo tempo, nominalmente gado e terra. Os zulus interpretaram a negociação como centrada no resgate do gado, atribuindo-lhe, assim, uma premissa hostil. De fato, o gado dos bôeres havia sido apreendido por Mzilikazi e, na

Campbell Africana Library, 1976, v. 5, p. IX-X; e HAMILTON, Carolyn. Backstory, biography, and the life of the James Stuart Archive. History in Africa. Cambridge: Cambridge University Press, 2011, v. 38, p. 326.

14 Os "bôeres" [trekkers comandados por Andries Hendrik Potgieter] consideravam que o gado lhes pertencia porque haviam entrado em conflito com Mzilikazi pela posse das terras no entorno dos montes Heidelberg, tendo perdido uma parte de seu rebanho na batalha de Vegkop, em outubro de 1836. No ano seguinte, encerrando um curto período de dispersão dos regimentos que se seguiu após ter assumido a sucessão de Shaka em 1828, Dingana retomou os ataques com os quais buscava reforçar o seu poder, incluindo o de 1837 contra Mzilikazi. sequência, por Dingana, mas já não tinham nenhum direito de reivindicação, ainda que lhe pertencesse em primeira instância”. ${ }^{15}$

Nesse ponto, Stuart vinculava o encontro de outubro de 1837 à morte de Piet Retief em fevereiro de 1838, na sua segunda visita à povoação de Dingana, destinada a firmar a cessão do território ao sul do rio Thukela, tal como a já referida devolução do gado. Ao ataque ao grupo de Retief, seguiram-se outros aos acampamentos "bôeres" próximos à então colônia britânica de Natal, mas em dezembro de 1838, organizados em torno de Andries Pretorius, os "boer trekkers" infligiram uma pesada derrota às forças de Dingana, na batalha de Ncome (Blood) River. ${ }^{16}$

Em seu retrospecto, James Stuart tece o argumento sobre o erro "estratégico" dos "bôeres" fundindo-o à narrativa de Tununu. Sobre o seu julgamento é possível que tenham influído o vínculo com os signos de identificação do domínio britânico e a projeção de ascendência, especialmente mobilizados na segunda guerra anglo-bôer (18991902), assim como a sua defesa em relação ao conhecimento das "instituiçóes e práticas africanas" na definição da política colonial, sugerindo o quão desastroso podia se revelar desconsiderá-las. Entre todos os pontos, entretanto, o que sobressai é o modo como

\footnotetext{
${ }^{15}$ WEBB, Colin de Berri; WRIGHT, John Britten. The James Stuart Archive of recorded oral evidence relating to the history of the zulu and neighbouring peoples. Pietermaritzburg: University of Natal Press and Durban: Killie Campbell Africana Library, 2014 , v. 6, p. 261. (tradução livre)

16 ETHERINGTON, Norman. The great treks: the transformation of southern Africa, 1815-1854. Londres: Longman, 2001, p. 279-280.
} 
Stuart se integra à cadeia de transmissão que Tununu invoca para si, ainda que instilando enquadramentos em suas referências a "tribos", "raças nativas" e ao eterno presente em que viviam os seus entrevistados, "preocupados apenas com as questóes mais imediatas". ${ }^{17}$

Tununu, que à época de entrevista tinha cerca de 90 anos, nasceu entre 1811 e 1812, no tempo em que Dingana (em conflito com Shaka pela sucessão de Senzangakona) havia sido acolhido por seu pai: "eu o conhecia bem. (...) E veio dele o meu nome. $\mathrm{Na}$ época em que nasci havia uma escassez severa de alimentos. Os Izitununu [andarilhos] vagavam com fome por várias partes, carregando ou procurando por comida. Eles sofriam muito. Uma manhã, ouvindo as esposas de meu pai rindo, Dingana, saiu de seu ilawu [palhota ocupada por meninos e homens não casados], perguntando o que estava acontecendo. Contaram-lhe que uma das mulheres havia dado à luz um menino. Esse menino era eu mesmo. Por isso, Dingana me deu o nome de Tununu" ${ }^{18}$

Mais do que estabelecer a referência temporal de seu nascimento, o ato de nomeá-lo assumiu para Tununu o sentido de um rito de ligação com Dingana, atualizado a cada evocação da memória. Ele tornou-se inceku de Dingana — seu ajudante e auxiliar pessoal, executando tarefas de ordenha, de cuidado com animais abatidos e manutenção da palhota. E quando, em 1838, Dingana atacou o grupo de Piet Retief, Tununu lutou pelo regimento Imkulutshana, do qual fazia parte, e, novamente, em Ncome. ${ }^{19}$

Para a narrativa de Tununu converge, portanto, a força do que lhe transmitiu Dingana — "eu ouvi essas coisas dele próprio" — e é em relação a esse vínculo que produz os contextos de significação de sua história e faz ressoar as escolhas de seu pai. Ao atribuir coerência às suas decisões — Dingana estava preparado para dar [aos "bôeres"] estas coisas (...) [mas] o gado apreendido de Mzilikazi já tinha sido distribuído e, portanto, não era possível restituí-lo" —, Tununu produz, também ele, um discurso de poder, incorporado por Stuart em sua escrita. E, nesse sentido, a falta de marcação formal em algumas passagens, distinguindo a autoria das falas, revela, talvez, o valor maior da coleção - o entrelaçamento inevitável das experiências históricas em contextos africanos.

\footnotetext{
${ }^{17}$ WEBB, Colin de Berri; WRIGHT, John Britten. The James Stuart Archive of recorded oral evidence relating to the history of the zulu and neighbouring peoples, op. cit. (2014), p. 264. (tradução livre)

${ }^{18} \mathrm{Ibidem}$, p. 253. (tradução livre)
}

${ }^{19}$ Ibidem, p. 252-253; 268. (tradução livre) 